\title{
Acetylcholinesterase protein level is preserved in the
}

\section{Alzheimer's brain}

María-Letizia Campanari ${ }^{1,2}$, María-Salud García-Ayllón ${ }^{1,2,3}$, Lidia Blazquez-Llorca ${ }^{4,5}$, Wilson K.W. Luk ${ }^{6}$, Karl Tsim ${ }^{6}$, and Javier Sáez-Valero ${ }^{1,2}$

${ }^{1}$ Instituto de Neurociencias de Alicante, Universidad Miguel Hernández-CSIC, Sant Joan d’Alacant, E-03550, Spain; ${ }^{2}$ Centro de Investigación Biomédica en Red sobre Enfermedades Neurodegenerativas (CIBERNED), Spain; ${ }^{3}$ Unidad de Investigación, Hospital General Universitario de Elche, FISABIO, Elche, Spain; ${ }^{4}$ Laboratorio Cajal de Circuitos Corticales (CTB), Universidad Politécnica de Madrid, Campus Montegancedo, Pozuelo de Alarcón, Spain; ${ }^{5}$ Instituto Cajal (CSIC), Madrid, Spain; ${ }^{6}$ Department of Biology and Center for Chinese Medicine, The Hong Kong University of Science and Technology, Clear Water Bay Road, Hong Kong, China.

*Corresponding author: Javier Sáez-Valero, Instituto de Neurociencias, Universidad Miguel Hernández-CSIC, E-03550 Sant Joan d’Alacant, Spain. Tel.:+34 96591 9580, Fax:+34 96591 9561, E-mail: j.saez@umh.es.

Running title: AChE protein in the Alzheimer's brain

Key Words: Alzheimer's disease, acetylcholinesterase, $\beta$-amyloid, presenilin 1.

Number of words, Abstract: $205 \mathrm{w} \quad$ Manuscript: $~ 3000 \mathrm{w}$

Number of Figures: 2 Figures 


\section{ABSTRACT}

Acetylcholinesterase (AChE) is a key enzyme in the cholinergic nervous system, and is one of the most studied proteins in the field of Alzheimer's disease (AD). Moreover, alternative functions of AChE unrelated with the hydrolysis of acetylcholine are suspected. Until now, the majority of investigation on AChE in AD pathology has been focus in the determination of its enzymatic activity level, which is depleted in the AD brain. Despite this overall decrease, AChE activity increases at the vicinity of the two hallmarks of $\mathrm{AD}$, the amyloid plaques and the neurofibrillary tangles (NFT). In fact, AChE may directly interact with $A \beta$ in a manner that increases the deposition of $A \beta$ to form plaques. In the context of protein-protein interactions, we have recently reported that AChE can interact with presenilin-1, the catalytic component of $\gamma$-secretase, influencing its expression level and also its activity. However, the alteration of AChE protein in AD brain has not been determined. Here, we demonstrated by Western blotting and immunohistochemistry that a prominent pool of enzymatically inactive AChE protein was existed in the AD brain. The potential significance of these unexpected levels of inactive AChE protein in the AD brain was discussed, especially in the context of protein-protein interactions with $\beta$-amyloid and presenilin-1. 


\section{Introduction}

Alzheimer's disease (AD) is a neurodegenerative disorder characterized by progressive loss of memory and cognition. Cholinergic depletion is a classical feature in the AD brain, associated with amyloid plaques and neurofibrillary tangles (NFT) (Davies and Maloney, 1976; Perry et al., 1977). A decrease in acetylcholinesterase (AChE), the enzyme that rapidly degrades the neurotransmitter acetylcholine at cholinergic synapses, has been reported in a large number of studies (for a review see GarcíaAyllón et al., 2011). Nonetheless, because the substantial reduction in acetylcholine levels, a molecule with a critical role in cognitive function, the therapies designed to reverse the cholinergic deficit characteristics of $\mathrm{AD}$ are based on inhibitors of AChE (AChE-I) (Giacobini, 2003; Lleó et al., 2006). Furthermore, evidence indicates that cholinergic mechanisms can modulate amyloid metabolism (Nitsch et al., 1992; Rossner et al., 1998) and AChE-Is affect the amyloid expression (Mori et al., 1995;

Zimmermann et al., 2005; Lahiri et al., 1997). Although, the therapeutic effect of present AChE-I drugs used in AD therapy is rather modest and has not met expectations (Small, 2005),

The majority of investigation about AChE on AD progression and therapy has been based in the determination of its enzymatic activity level. However, AChE is much more than a cholinergic enzyme, and indeed other biological functions unrelated with its catalytic activity have been reported (Sternfeld et al., 1998; Dori et al., 2005; Grisaru et al., 2006). These alternative functions are probably related with the rich polymorphism of AChE that exists in different variants by alternative splicing, as well as the existence of different molecular forms (for a review see Massoulié, 2002). Moreover, AChE is present in non-cholinergic tissues and shares with several neural cell adhesion proteins high sequence similarity (Krejci et al., 1991). The presence of a 
cholinesterase-like domain in those adhesion proteins may reflect the capacity of AChE in acting as protein-protein interactions.

We have recently demonstrated an interaction between AChE and presenilin-1 (PS1), the catalytic component of the $\gamma$-secretase complex (Silveyra et al., 2008; 2012a). $\gamma$-Secretase is a proteolytic enzymatic complex that participates in the processing of the amyloid precursor protein (APP), generating the $\beta$-amyloid peptide or A $\beta$ (Kaether et al., 2006), the major constituent of the amyloid plaques (Masters et al., 1985; Kang et al., 1987). Moreover, extensive studies by Inestrosa and co-workers showed that AChE directly interacted with A $\beta$ (Alvarez et al., 1995; Inestrosa et al., 1996a; 1996b). Indeed, despite the overall decrease in the AD brain, AChE is increased at the vicinity of amyloid plaques and NFT (Ulrich et al., 1990; Gomez-Ramos et al., 1992; Wright et al., 1993). The pathological implications of these and other AChE-amyloid interrelationships have remained elusive, but this is evident that AChE can influence amyloid processing and fibrillation via protein-protein interactions and not only through its cholinergic activity. Accordingly, new dual binding AChE-I, able to inhibit the AChE-induced A $\beta$ aggregation, are in development (García-Palomero et al., 2008; Belluti et al., 2011; Viayna et al., 2013). In this context, recently has been demonstrated that a novel AChE-I, NP-9 (9-anthraldehyde pyrazoline derivative), which is able to interfere $A \beta$ AChE interaction, attenuates $A \beta$ aggregation and amyloid-induced toxicity in Alzheimer’s animal models (Mishra et al., 2013).

Surprisingly, the vast majority of AChE studies in the AD brain, including histological studies, are focus on the AChE enzymatic level and not the protein level. Here, we present evidence that, in the AD brain, the level of AChE protein does not accord with the decrease in enzymatic activity level. We also discuss the potential physiopathological consequences of the presence of this unexpected large pool of nonenzymatically active AChE in the pathological brain. 


\section{Material and methods}

\section{Collection of human brain samples}

This study was approved by the ethics committee of the Miguel Hernandez University, and was carried out in accordance with the Declaration of Helsinki. Frozen brain samples [five AD cases, aged 78-91 years (mean 83 years), and five control cases; aged 60-73 years (mean 66 years)] were obtained from the UIPA neurological tissue bank (Unidad de Investigación Proyecto Alzheimer; Madrid, Spain). Fixed human brain tissues [four AD cases, aged 75-82 years (mean 80), and one control cases; aged 69 years] were obtained from the UIPA neurological tissue bank, the Instituto de Neuropatología (IDIBELL-Hospital Universitario de Bellvitge, Barcelona, Spain) and from the Servicio de Patología Forense (Instituto Vasco de Medicina Legal, Bilbao, Spain). After neuropathological examination, sporadic AD cases were categorized as stages V-VI of Braak and Braak (Braak and Braak, 1991). Samples from non-disease individuals correspond to cases with no clinical dementia and no evidence of brain pathology. The mean postmortem interval of the tissue was between 1.5 and $6 \mathrm{~h}$, with no significant difference between each group of samples.

\section{Preparation of human brain samples for biochemical analysis}

Samples ( 0.1 g) of human frontal cortex, stored at $-80{ }^{\circ} \mathrm{C}$, were thawed slowly at $4^{\circ} \mathrm{C}$ and homogenized (10\% v/v) in 50 mM Tris-HCl, pH 7.5 / 150 mM NaCl / 5 mM EDTA / 1\% (w/v) Nonidet P-40 / 0.5\% (w/v) Triton X-100 and supplemented with a cocktail of protease inhibitors (Sáez-Valero et al., 1993). The homogenates were sonicated and centrifuged at $70000 \times \mathrm{g}$ at $4{ }^{\circ} \mathrm{C}$ for $1 \mathrm{~h}$, and the supernatants were collected and frozen at $-80{ }^{\circ} \mathrm{C}$ until assay. 


\section{AChE enzymatic assay and protein determination}

A modified microassay version of the colorimetric Ellman's method was used to measure AChE (Sáez-Valero et al., 1993), using $50 \mu \mathrm{M}$ tetraisopropyl pyrophosphoramide (iso-OMPA) as specific inhibitor for the structurally related butyrylcholinesterase, an enzyme that coexists with AChE in the human brain. One milliunit (mU) of AChE activity was defined as the number of nmoles of acetylthiocholine hydrolyzed per minute at $22^{\circ} \mathrm{C}$. Total protein concentrations were determined using the bicinchoninic acid method (Pierce). AChE specific activity is expressed as the activity of the enzyme in mU per milligram (mg) of total protein (mU/mg).

\section{Western blotting assays}

Fifty micrograms of protein from brain extracts (equal amount of protein in each lane) were separated by SDS-PAGE electrophoresis. Samples were denatured at $98{ }^{\circ} \mathrm{C}$ for 7 min. The separated proteins were transferred to nitrocellulose membranes (Schleicher \& Schuell Bioscience GmbH) and probed with the goat anti-AChE antibody N19 (Santa Cruz Biotech) and rabbit anti-glyceraldehyde 3-phosphate dehydrogenase (GAPDH) (Abcam). The blots were incubated with the corresponding secondary antibody conjugated to horseradish peroxidase and the signal was detected using ECL Plus detection reagent according to the manufacturer's instructions (GE Healthcare) in a Luminescent Image Analyzer LAS-1000 Plus (FUJIFILM). For semi-quantitative analysis, protein levels were normalized to GAPDH, and the intensity of bands was measured by densitometry with the Science Lab Image Gauge v4.0 software provided by FUJIFILM. 
Upon removal, the brain tissue was immediately fixed in cold 4\% paraformaldehyde in phosphate buffer (PB: 0.1 M, pH 7.4), and after 2 h, the tissue was cut into small blocks and post-fixed in the same fixative for $24-48 \mathrm{~h}$ at $4{ }^{\circ} \mathrm{C}$. After fixation, all the specimens were immersed in graded sucrose solutions, and they were stored in a cryoprotectant solution at $-20^{\circ} \mathrm{C}$. Serial vibratome sections $(50 \mu \mathrm{m})$ of cortical tissue were obtained, and the sections from each region and case were batch-processed for immunocytochemical staining. The sections immediately adjacent to those stained immunocytochemically were Nissl-stained as to identify the cortical areas to which they pertained and the laminar boundaries. Same AD and ND case were extensive studied by scores for the amyloid and neurofibrillary pathologies, as in a previous study (BlazquezLlorca et al., 2011).

\section{Immunohistochemistry and staining procedure}

Free-floating hippocampal sections were pre-treated in $1 \% \mathrm{H}_{2} \mathrm{O}_{2}$ for 30 min to remove endogenous peroxidase activity, and subsequently they were blocked for $1 \mathrm{~h}$ in phosphate buffer (PB) with $0.25 \%$ Triton-X and 3\% normal rabbit serum (1:200, Vector Laboratories Inc.). The sections were incubated overnight at $4{ }^{\circ} \mathrm{C}$ with the N19 (1:500) antibody and the following day, the sections were rinsed and incubated for $2 \mathrm{~h}$ with biotinylated rabbit anti-goat IgG (1:200, BA-5000, Vector Laboratories). The sections were then incubated for $1 \mathrm{~h}$ in an avidin-biotin peroxidase complex (Vectastain ABC Elite PK6100, Vector), and finally with the 3,3'-diaminobenzidine tetrahydrochloride chromogen (DAB, Sigma-Aldrich). After staining, the sections were dehydrated, cleared with xylene and coverslipped. Control sections were processed as above but without the primary antibodies, and no significant staining was seen under these conditions. 
The AChE enzymatic reaction was performed according to the method of Karnovsky and Roots (Karnovsky and Roots, 1964). Slices were incubated for $2 \mathrm{~h}$ in the medium containing: acetylthiocholine iodide (0.05\%), $5 \mathrm{mM} \mathrm{K}_{3} \mathrm{Fe}(\mathrm{CN})_{4}(0.164 \%), 30$ $\mathrm{mM} \mathrm{CuSO} 4(0.75 \%)$, and $0.1 \mathrm{mM}$ sodium citrate (2.94\%) in $0.2 \mathrm{M}$ acetate buffer (pH 6.0) $(1.64 \%)$. The reaction was stopped with washes in phosphate-buffered saline. Then, the sections were dehydrated, cleared with xylene and coverslipped.

\section{Statistical analysis}

All data were analyzed using SigmaStat (Version 2.0; SPSS Inc.) by Student’s t-test (two tailed). Results are presented as means \pm SEM. $p$ values $<0.05$ were considered significant. 


\section{Results}

The level of AChE in frontal cortex extracts from AD and ND subjects were screened for enzymatic activity. As expected, the AChE assay revealed that AD samples had lower enzymatic activity (40\% decrease; $p=0.003)$, in comparison to age and gendermatched ND controls (Fig. 1A).

Sample aliquots were analyzed by SDS-PAGE under fully reducing conditions, followed by Western blotting using anti-AChE antibody N19, raised against a peptide that maps the N-terminus of human AChE, common to all variants. N19 detected AChE bands of $\sim 75$ and $\sim 65 \mathrm{kDa}$, and a doublet of bands at $\sim 55$ and $\sim 50 \mathrm{kDa}$ in brain samples from both $\mathrm{AD}$ and non-disease (ND) control subjects (Fig. 1B). Although the predicted molecular weight of the AChE subunits is $\sim 70 \mathrm{kDa}$ in size, our as well as other studies strongly suggest the identity of lower AChE molecular weight bands (García-Ayllón et al., 2006; 2007; 2010; 2012; Santos et al., 2007; Sternfeld et al., 2000; Xie et al., 2011). The lower molecular weight bands might originate by post-translation modification and/or resulted from the reducing conditions used during electrophoresis. We have previously confirmed the specificity of the AChE bands, including the lighter subunits, by AChE immunoprecipitation and probing blots with alternative anti-human AChE antibodies (García-Ayllón et al., 2007; 2010). Interestingly, the decrease in AChE enzyme activity was not paralleled by changes in AChE protein immunoreactivity. The levels of immunoreactive AChE bands were not significantly different in AD samples in comparison with ND controls (Fig. 1B).

Immunohistochemical examination of AD brain yielded similar results (Fig. 2). The AChE protein staining pattern was studied in hippocampus from $3 \mathrm{AD}$ patients and one ND control case. Sections from AD and control brain showed similar immunoreactivity to the anti-AChE antibody N19. Moreover, AChE-positive fibers stained with the N19 antibody seemed to be denser around amyloid plaques in AD 
patients (Fig. 2B), when compared with other regions far from plaque or the control case. Similarly to previous reports (Ulrich et al., 1990; Gomez-Ramos et al., 1992; Wright et al., 1993), when the AChE enzymatic reaction was performed by the Karnovsky and Roots method (Karnovsky and Roots, 1964), no fibers were observed, but the amyloid plaques and NFT were stained (Fig. 2B, inset). 


\section{Discussion}

Here we report that AChE protein level appears unexpectedly preserved in the AD brain, respect to the decline in activity level. Frontal cortex samples, assayed by immunoblotting, and hippocampus sections, resolved by immunohistochemistry, demonstrate that AChE protein levels are comparable between AD and ND subjects. Despite the limitation of the low number of samples analyzed, our data signify discrepancies between the levels of AChE activity and AChE protein immunoreactivity, which may be attributable in part to the inactive or subnormal active character of AChE subunits present in the pathological tissues. Moreover, AChE banding pattern obtaining by electrophoretic analysis/Western blotting has no simple relationship to specific molecular forms or enzymatic activity (García-Ayllón et al., 2006; 2007). For this reason, the detriment in the major tetrameric form of AChE is not patent in immunoreactivity changes of particular bands. Further analyses with antibodies for specific variants are pending.

There is extensive number of investigations in effort to identify alterations in AChE level as a consequence of AD processes. Most of them based on biochemical determination of enzymatic activity, probably because the facility in measuring the activity of the enzyme, and also because the interest derived from the use of AChE-I in therapy. Today it is well established that substantial loss of AChE activity is due to loss of a tetrameric form linked to the plasma membrane (Atack et al., 1983; Sáez-Valero et al., 1999). Enzymatic histochemical examination of AD brain yielded similar results than biochemical determination with an overall depletion of AChE activity (Ulrich et al., 1990; Gomez-Ramos et al., 1992; Wright et al., 1993). In vivo studies by positron emission tomography, based in the assessment of enzymatic activity using radiolabeled 
analogues of acetylcholine, also suggested that AChE activity could be reduced in the AD brain (Iyo et al., 1997; Herholz, 2008; Mori et al., 2012).

Several laboratories attempted to develop and enzyme-linked immunosorbent assay (ELISA) for AChE (Rasmussen et al., 1989; Blennow et al., 2007; Darreh-Shori et al., 2008), but very few develop a two-site immunoassay (Brimijoin et al., 1987; Weikert et al., 1994; Konings et al., 1995). Hammond and Brimijoin (1998) reported a parallel variation in AChE enzyme activity and AChE immunoreactivity, assessed by a two-site ELISA in the AD brain, but this ELISA probably assessed only protein levels for the major tetrameric form. Previously, we had noted that a large amount of AChE subunits found in AD samples, and identified by Western blotting with several polyclonal anti-AChE antibodies, displayed low affinity for certain monoclonal antibodies, which recognized native AChE (Sáez-Valero et al., 2000; García-Ayllón et al., 2007; 2010). As commented above, the lack of correlation between catalytic activity and immunostaining may be attributable, at least in part, to the presence of large amount of inactive AChE subunits.

The existence of inactive AChE has been demonstrated in brain (Chatel et al., 1993). These inactive AChE species are probably monomers, which could serve a reservoir for the active enzyme (Stieger, et al., 1987; Rotundo, 1988). Anyhow, the presence of large amount of inactive monomers in fluids, such as cerebrospinal fluid (CSF) and plasma (Darreh-Shori et al., 2004; García-Ayllón et al., 2007; 2010), suggests that these light species might have more than a simple role as precursors of enzymatically active oligomers. Despite several evidences strongly supports the possibility that AChE can act independently of acetylcholine hydrolysis, the physiological significance of the non-enzymatic AChE in the brain still is controversial, as catalytic and non-catalytic effects cannot be easily distinguished (reviewed in Massoulié et al., 1993; Balasubramanian and Bhanumathy, 1993; Small et al., 1996; 
Layer, 1995; Soreq and Seidman, 2001; Greenfield et al., 2008). Indeed, transgenic over-expression of enzymatically inactivate AChE (Sternfeld et al., 1998; Dori et al., 2005; Grisaru et al., 2006) or heat-inactivated AChE (Klegeris et al., 1994) have demonstrated to exert distinct biological functions. Possible biological functions for the pool of AChE non-enzymatically active in the normal brain, and particularly in the AD brain, therefore need to be elucidated.

The occurrence of AChE subnormal active in the pathological tissue cannot be discarded. In this context, AChE activity present in the AD brain associated with plaques and NFT display particular enzymatic properties and sensitivity to inhibitors (Geula and Mesulam, 1989; Wright et al., 1993). However, it is not clear whether the atypical histochemical behavior of AChE observed in AD is due to alterations in kinetic properties of these enzymes (Ciro et al., 2012), or due to interactions with other molecules within these lesions (Darvesh et al., 2010). In the context of the presence of AChE within plaques and NFT, it is important to note that both $\mathrm{AD}$ effectors, $\mathrm{A} \beta$ and abnormally hyperphosphorylated tau, can influence AChE levels in vitro (Sberna et al., 1997; Sáez-Valero et al., 2003; Hu et al., 2003; Melo et al., 2003) and in rodent models (Sberna et al., 1998; Sáez-Valero et al., 2002; Silveyra et al., 2012b; Kreutz et al., 2013). We have also demonstrated that $A \beta$ alters $A C h E$ glycosylation in vivo (Sberna et al., 1998; Fodero et al., 2002), and this change is similar to the change in the glycosylation pattern of AChE in AD brain (Sáez-Valero 1997; 1999; 2000). Correct glycosylation determines the adequate biological function by influencing trafficking, folding, assembly and final localization of glycoproteins. Changes in glycosylation could compromises enzymatic capacities. The glycosylation pattern of the inactive AChE pool in the Alzheimer's condition has not been studied.

Non-catalytic AChE is not the unique AChE pool that remains unaltered, or even increase, in the AD brain. The significance of different variants and forms of 
AChE is intriguing, as their specific subcellular distribution is thought to reflect specific physiological functions. Despite the loss of the major tetrameric and cholinergic AChE, the minor monomeric form increases in respect to the normal levels in non-pathological brain (Atack et al., 1983; Arendt et al., 1992; Sáez-Valero et al., 1999). So far, the significance of an increase in minor AChE species is controversial, as the relative increase is compared in absolute terms with the major cholinergic form. However, a variation in a particular AChE forms (with little impact on cholinergic equilibrium) could have impact at functional level with biological consequences, since particular forms or variants may have specific functions. Indeed, recent evidences indicate distinct, and in certain cases inverse cell fate outcome under enforced expression of the human N- and C-terminally modified AChE variants, all of which have similar enzymatic activities (Berson et al., 2008; Toiber et al., 2008; Greenberg et al., 2010). Brain AChE splice variants show indistinguishable enzymatic activity, but may present particular banding pattern by Western blotting (Meshorer and Soreq H, 2006). Additional studies regarding the specific roles of particular AChE species is mandatory in other to develop more effective therapies. In this regard, targeting a specific AChE variant (e.g. by antisense or siRNA agents) could hence offer specific advantages. Indeed, the AChE-targeted microRNA-132 has been recently reported to be downregulated during the progression of $\mathrm{AD}$ (Lau et al., 2013); and the possibility to intercept microRNA-132-mediated damages by modulating AChE expression has been demonstrated viable (Shaltiel et al., 2013).

The interaction of AChE with the catalytic subunit of the $\gamma$-secretase complex, PS1, it is also of interest. We have demonstrated the reciprocal co-immunoprecipitation of AChE with PS1 (Silveyra et al., 2008), and the modulation of PS1 levels by AChE-I (Silveyra et al., 2012a). More interestingly, we have recently seen changes in PS1 levels under the influence of AChE genetic expression (Silveyra et al., 2012a), even using of 
inactive catalytic mutants of the enzyme (unpublished). The modulatory effect on PS1 levels was not sustained when AChE-I promotes feed-back AChE up-regulation (Silveyra et al., 2012b). All together these results suggest that excess of inactive or inactivated brain AChE can exert a variety of unpredictable effects, and maybe induce vulnerability in the pathological brain.

In conclusion, a better understanding of the alternative functions of AChE and estimation of its protein levels could be relevant for deciphering their implication in the progression of Alzheimer's pathology and development of new therapy. 


\section{Acknowledgments.}

We thank Drs. A. Rábano (Fundación CIEN, Spain), I. Ferrer (Servicio de Anatomía Patológica, IDIBELL-Hospital Universitario de Bellvitge, Barcelona, Spain) and R. Alcaraz (Instituto Vasco de Medicina Legal, Bilbao, Spain) for assistance with human brain samples. We also thank Dr. Javier Defelipe (Laboratorio Cajal de Circuitos Corticales, Universidad Politécnica de Madrid, Spain) for technical facilities and advice. MLC is supported by a Consolider-Predoctoral fellowship from the CSIC, Spain. This work was supported by grants from Fundación CIEN-Reina Sofía, Fondo de Investigaciones Sanitarias (FIS; Grant PS09/00684) from Spain to JSV; and Fondo de Investigaciones Sanitarias (FIS; Grant CP11/00312) to MSGA. 


\section{REFERENCES}

Atack J.R., Perry E.K., Bonham J.R. et al. (1983) Molecular forms of acetylcholinesterase in senile dementia of Alzheimer type: selective loss of the intermediate (10S) form. Neurosci Lett. 30, 199-204.

Alvarez A., Bronfman F., Pérez C.A., Vicente M., Garrido J., Inestrosa N.C. (1995) Acetylcholinesterase, a senile plaque component, affects the fibrillogenesis of amyloid-beta-peptides. Neurosci Lett. 201, 49-52.

Arendt T., Brückner M.K., Lange M., Bigl V. (1992) Changes in acetylcholinesterase and butyrylcholinesterase in Alzheimer's disease resemble embryonic developmenta study of molecular forms. Neurochem Int. 21, 381-396.

Balasubramanian A.S., Bhanumathy C.D. (1993) Noncholinergic functions of cholinesterases. FASEB J. 7, 1354-1358.

Belluti F., Bartolini M., Bottegoni G., et al. (2011) Benzophenone-based derivatives: a novel series of potent and selective dual inhibitors of acetylcholinesterase and acetylcholinesterase-induced beta-amyloid aggregation. Eur. J. Med. Chem. 46, 1682-1293.

Berson A., Knobloch M., Hanan M. et al. (2008) Changes in readthrough acetylcholinesterase expression modulate amyloid-beta pathology. Brain 131, 109119.

Blazquez-Llorca L., Garcia-Marin V., Merino-Serrais P., Avila J. and DeFelipe J. (2011) Abnormal Tau Phosphorylation in the Thorny Excrescences of CA3 Hippocampal Neurons in Patients with Alzheimer’s Disease. Journal of Alzheimer's Disease 26, 683-698.

Blennow K., Zetterberg H., Minthon L. et al. (2007) Longitudinal stability of CSF biomarkers in Alzheimer's disease. Neurosci Lett. 419, 18-22. 
Braak H. and Braak E. (1991) Neuropathological stageing of Alzheimer-related changes. Acta Neuropathol. 82, 239-259.

Brimijoin S., Hammond P. and Rakonczay Z. (1987) Two-site immunoassay for acetylcholinesterase in brain, nerve, and muscle. J Neurochem. 49, 555-562.

Chatel J.M., Grassi J., Frober, Y., Massoulié J., Vallette F.M. (1993) Existence of an inactive pool of acetylcholinesterase in chicken brain. Proc. Natl. Acad. Sci. USA 90, 2476-2480.

Ciro A., Park J., Burkhard G., Yan N., Geula C. (2012) Biochemical differentiation of cholinesterases from normal and Alzheimer's disease cortex. Curr. Alzheimer Res. 9, 138-143.

Darreh-Shori T., Hellström-Lindahl E., Flores-Flores C., et al. (2004) Long-lasting acetylcholinesterase splice variations in anticholinesterase-treated Alzheimer's disease patients. J. Neurochem. 88, 1102-1113.

Darreh-Shori T., Kadir A., Almkvist O. et al. (2008) Inhibition of acetylcholinesterase in CSF versus brain assessed by 11C-PMP PET in AD patients treated with galantamine. Neurobiol. Aging 29, 168-184.

Darvesh S., Reid G.A., Martin E. (2010) Biochemical and histochemical comparison of cholinesterases in normal and Alzheimer brain tissues. Curr Alzheimer Res. 7, 386400.

Davies P. and Maloney A.J.F. (1976) Selective loss of central cholinergic neurons in Alzheimer's disease. Lancet 2, 1403.

Dori A., Cohen J., Silverman W.F., Pollack Y., Soreq H. (2005) Functional manipulations of acetylcholinesterase splice variants highlight alternative splicing contributions to murine neocortical development. Cereb. Cortex 15, 419-430. 
Fodero L.R., Sáez-Valero J., McLean C.A.et al. (2002) Altered glycosylation of acetylcholinesterase in APP (SW) Tg2576 transgenic mice occurs prior to amyloid plaque deposition. J. Neurochem. 81, 441-448.

García-Ayllón M.S., Silveyra M.X., Candela A. et al. (2006) Changes in liver and plasma acetylcholinesterase in rats with cirrhosis induced by bile duct ligation. Hepatology 43:444-453.

García-Ayllón M.S., Silveyra M.X., Andreasen N., Brimijoin S., Blennow K., SáezValero J. (2007) Cerebrospinal fluid acetylcholinesterase changes after treatment with donepezil in patients with Alzheimer's disease. J Neurochem. 10:1701-1711.

García-Ayllón M.S., Riba-Llena I., Serra-Basante C., Alom J., Boopathy R., SáezValero J. (2010) Altered levels of acetylcholinesterase in Alzheimer plasma. PLoS One 5, e8701.

García-Ayllón M.S., Small D.H., Avila J., Sáez-Valero J. (2011) Revisiting the Role of Acetylcholinesterase in Alzheimer's Disease: Cross-Talk with P-tau and $\beta$ Amyloid. Front. Mol. Neurosci. 4, 22.

García-Ayllón M.S., Millán C., Serra-Basante C., Bataller R., Sáez-Valero J. (2012) Readthrough acetylcholinesterase is increased in human liver cirrhosis. PLoS One 7, e44598.

García-Palomero E., Muñoz P., Usan P., et al., (2008) Potent beta-amyloid modulators. Neurodegener. Dis. 5, 153-156.

Geula C. and Mesulam M. (1989) Special properties of cholinesterases in the cerebral cortex of Alzheimer's disease. Brain Res. 498, 185-189.

Giacobini E. (2003) Cholinergic function and Alzheimer's disease. Int. J. Geriatr. Psychiatry 18, 1-5. 
Gomez-Ramos P., Mufson E.J., Moran M.A. (1992) Ultrastructural localization of acetylcholinesterase in neurofibrillary tangles, neuropil threads and senile plaques in aged and Alzheimer's brain. Brain Res. 569, 229-237.

Greenberg D.S., Toiber D., Berson A., Soreq H. (2010) Acetylcholinesterase variants in Alzheimer's disease: from neuroprotection to programmed cell death. Neurodegener. Dis. 7, 60-63.

Greenfield S.A., Zimmermann M., Bond C.E. (2008) Non-hydrolytic functions of acetylcholinesterase. The significance of C-terminal peptides. FEBS J. 275, 604611.

Grisaru D., Pick M., Perry C. et al. (2006) Hydrolytic and nonenzymatic functions of acetylcholinesterase comodulate hemopoietic stress responses. J. Immunol. 176, 27-35.

Hammond P. and Brimijoin S. (1988) Acetylcholinesterase in Huntington's and Alzheimer's diseases: simultaneous enzyme assay and immunoassay of multiple brain regions. J. Neurochem. 50, 1111-1116.

Herholz K. (2008) Acetylcholine esterase activity in mild cognitive impairment and Alzheimer's disease. Eur. J. Nucl. Med. Mol. Imaging 35, 25-29.

Hu W., Gray N.W., Brimijoin S. (2003) Amyloid-beta increases acetylcholinesterase expression in neuroblastoma cells by reducing enzyme degradation. J. Neurochem. 86, 470-478.

Inestrosa N.C., Alvarez A., Pérez C.A. et al. (1996a) Acetylcholinesterase accelerates assembly of amyloid-beta-peptides into Alzheimer's fibrils: possible role of the peripheral site of the enzyme. Neuron 16, 881-891.

Inestrosa N.C., Alvarez A., Calderón F. (1996b) Acetylcholinesterase is a senile plaque component that promotes assembly of amyloid beta-peptide into Alzheimer's filaments. Mol. Psychiatry 1, 359-361. 
Iyo M., Namba H., Fukushi K., Shinotoh H. et al. (1997) Measurement of acetylcholinesterase by positron emission tomography in the brains of healthy controls and patients with Alzheimer's disease. Lancet 349, 1805-1809.

Kaether C., Haass C., Steiner H. (2006) Assembly, trafficking and function of gammasecretase. Neurodegener. Dis. 3, 275-283.

Kang J., Lemaire H.G., Unterbeck A. et al. (1987) The precursor of Alzheimer's disease amyloid A4 protein resembles a cell-surface receptor. Nature 325, 733-736.

Karnovsky M.J. and Roots L. (1964) A "direct-coloring" thiocholine method for Cholinesterases. J. Histochem. Cytochem. 12, 219-221.

Klegeris A., Budd T.C., Greenfield S.A. (1994) Acetylcholinesterase activation of peritoneal macrophages is independent of catalytic activity. Cell. Mol. Neurobiol. 14, 89-98.

Konings C.H., Kuiper M.A., Mulder C., Calliauw J., Wolters E.C. (1995) CSF acetylcholinesterase in Parkinson disease: decreased enzyme activity and immunoreactivity in demented patients. Clin. Chim. Acta. 235, 101-105.

Krejci E., Duval N., Chatonnet A., Vincens P., Massoulié J. (1991) Cholinesterase-like domains in enzymes and structural proteins: functional and evolutionary relationships and identification of a catalytically essential aspartic acid. Proc. Natl. Acad. Sci. USA 88, 6647-6651.

Kreutz F., Scherer E.B., Ferreira A.G. et al. (2013) Alterations on Na+,K +-ATPase and Acetylcholinesterase Activities Induced by Amyloid- $\beta$ Peptide in Rat Brain and GM1 Ganglioside Neuroprotective Action. Neurochem. Res. 38, 2342-2350.

Lahiri D.K., Farlow M.R., Nurnberger J.I. Jr, Greig N.H. (1997) Effects of cholinesterase inhibitors on the secretion of beta-amyloid precursor protein in cell cultures. Ann. N. Y. Acad. Sci. 826, 416-421. 
Lau P., Bossers K., Janky R., et al. (2013) Alteration of the microRNA network during the progression of Alzheimer's disease. EMBO Mol. Med. 5, 1613-1634.

Layer P.G. (1995) Nonclassical roles of cholinesterases in the embryonic brain and possible links to Alzheimer disease. Alzheimer Dis. Assoc. Disord. 9, 29-36.

Lleó A., Greenberg S.M., Growdon J.H. (2006) Current pharmacotherapy for Alzheimer's disease. Annu. Rev. Med. 57:513-33.

Massoulié J., Pezzementi L., Bon S., Krejci E., Vallette F.M. (1993) Molecular and cellular biology of cholinesterases. Prog. Neurobiol. 41, 31-91.

Massoulié J. (2002) The origin of the molecular diversity and functional anchoring of cholinesterases. Neurosignals 11, 130-143.

Masters C.L., Simms G., Weinman N.A., Multhaup G., McDonald B.L., Beyreuther K. (1985) Amyloid plaque core protein in Alzheimer’s disease and Down syndrome. Proc. Natl. Acad. Sci. USA 82, 4245-4249.

Melo J.B., Agostinho P., Oliveira C.R. (2003). Involvement of oxidative stress in the enhancement of acetylcholinesterase activity induced by amyloid beta-peptide. Neurosci. Res. 45, 117-127.

Meshorer E., Soreq H. (2006) Virtues and woes of AChE alternative splicing in stressrelated neuropathologies. Trends Neurosci. 29, 216-224.

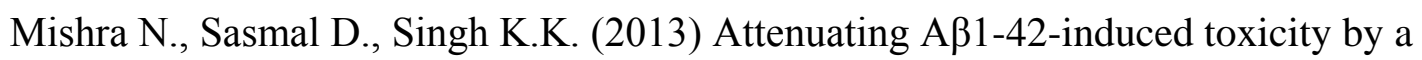
novel acetylcholinesterase inhibitor. Neuroscience 250, 309-319.

Mori F., Lai C.C., Fusi F., Giacobini E. (1995) Cholinesterase inhibitors increase secretion of APPs in rat brain cortex. Neuroreport 6, 633-636.

Mori T., Maeda J., Shimada H. et al. (2012) Molecular imaging of dementia. Psychogeriatrics 12, 106-114. 
Nitsch R.M., Slack B.E., Wurtman R.J., Growdon J.H. (1992) Release of Alzheimer amyloid precursor derivatives stimulated by activation of muscarinic acetylcholine receptors. Science 258, 304-307.

Perry E.K., Perry R.H., Blessed G., Tomlinson B.E. (1977) Necropsy evidence of central cholinergic deficits in senile dementia. Lancet 1, 189.

Rasmussen A.G., Arends J., Larsen S.O. (1989) Evaluation and quality control of a monoclonal antibody based enzyme antigen immunoassay of acetylcholinesterase in amniotic fluid. Scand. J. Clin. Lab. Invest. 49, 503-511.

Rossner S., Ueberham U., Schliebs R., Pérez-Polo J.R., Big, V. (1998) The regulation of amyloid precursor protein metabolism by cholinergic mechanisms and neurotrophin receptor signaling. Prog. Neurobiol. 56, 541-569.

Rotundo R.L. (1988) Biogenesis of acetylcholinesterase molecular forms in muscle. Evidence for a rapidly turning over, catalytically inactive precursor pool. J. Biol. Chem. 263, 19398-19406.

Sáez-Valero J., Tornel P.L., Muñoz-Delgado E., Vidal C.J. (1993) Amphiphilic and hydrophilic forms of acetyl- and butyrylcholinesterase in human brain. J. Neurosci. Res. 35, 678-689.

Sáez-Valero J., Sberna G., McLean C.A., Masters C.L., Small D.H. (1997) Glycosylation of acetylcholinesterase as diagnostic marker for Alzheimer's disease. Lancet 350, 929.

Sáez-Valero J., Sberna G., McLean C.A., Small D.H. (1999) Molecular isoform distribution and glycosylation of acetylcholinesterase are altered in brain and cerebrospinal fluid of patients with Alzheimer's disease. J. Neurochem. 72, 16001608. 
Sáez-Valero J., Mok S.S., Small D.H. (2000) An unusually glycosylated form of acetylcholinesterase is a CSF biomarker for Alzheimer's disease. Acta Neurol. Scand. 176, 49-52.

Sáez-Valero J., de Ceballos M.L., Small D.H., de Felipe C. (2002) Changes in molecular isoform distribution of acetylcholinesterase in rat cortex and cerebrospinal fluid after intracerebroventricular administration of amyloid betapeptide. Neurosci. Lett. 325, 199-202.

Sáez-Valero J., Fodero L.R., White A.R., Barrow C.J., Small D.H. (2003)

Acetylcholinesterase is increased in mouse neuronal and astrocyte cultures after treatment with beta-amyloid peptides. Brain Res. 965, 283-286.

Santos S.C., Vala I., Miguel C. et al. (2007) Expression and subcellular localization of a novel nuclear acetylcholinesterase protein. J. Biol. Chem. 282, 25597-25603.

Sberna G., Sáez-Valero J., Beyreuther K., Masters C.L., Small D.H. (1997) The amyloid b-protein of Alzheimer’s disease increases acetylcholinesterase expression by increasing intracellular calcium in embryonal carcinoma P19 cells. J. Neurochem. 69, 1177-1184.

Sberna G., Sáez-Valero J., Li Q.X. et al. (1998) Acetylcholinesterase is increased in the brains of transgenic mice expressing the C-terminal fragment (CT100) of the betaamyloid protein precursor of Alzheimer's disease. J. Neurochem. 71, 723-731.

Shaltiel G., Hanan M., Wolf Y., et al. (2013) Hippocampal microRNA-132 mediates stress-inducible cognitive deficits through its acetylcholinesterase target. Brain Struct. Funct. 218, 59-72.

Small D.H., Michaelson S., Sberna G. (1996) Non-classical actions of cholinesterases: role in cellular differentiation, tumorigenesis and Alzheimer's disease. Neurochem. Int. 28, 453-483. 
Small DH. (2005) Acetylcholinesterase inhibitors for the treatment of dementia in Alzheimer's disease: do we need new inhibitors? Expert. Opin. Emerg. Drugs. 10, 817-825.

Silveyra M.X., Evin G., Montenegro M.F. et al. (2008) Presenilin 1 interacts with acetylcholinesterase and alters its enzymatic activity and glycosylation. Mol. Cell. Biol. 28, 2908-2919.

Silveyra M.X., García-Ayllón M.S., Serra-Basante C., et al. (2012a) Changes in acetylcholinesterase expression are associated with altered presenilin-1 levels. Neurobiol. Aging 33, 627.e27-37.

Silveyra M.X., García-Ayllón M.S., De Barreda E.G. et al. (2012) Altered expression of brain acetylcholinesterase in FTDP-17 human tau transgenic mice. Neurobiol. Aging 33, 624.e23-34.

Soreq H., Seidman S. (2001) Acetylcholinesterase-new roles for an old actor. Nat. Rev. Neurosci. 2, 294-302.

Sternfeld M., Ming G., Song H. et al. (1998) Acetylcholinesterase enhances neurite growth and synapse development through alternative contributions of its hydrolytic capacity, core protein, and variable C termini. J. Neurosci. 18, 1240-1249.

Sternfeld M., Shoham S., Klein O., Flores-Flores C., Evron T., Idelson G.H., et al. (2000) Excess "read-through" acetylcholinesterase attenuates but the "synaptic" variant intensifies neurodeterioration correlates. Proc. Natl. Acad. Sci. USA 97, 8647-8652.

Stieger S., Brodbeck U., Witzemann V. (1987) Inactive monomeric acetylcholinesterase in the low-salt-soluble extract of the electric organ from Torpedo marmorata. J. Neurochem. 49, 460-467. 
Toiber D., Berson A., Greenberg D., Melamed-Book N., Diamant S., Soreq H. (2008) N-acetylcholinesterase-induced apoptosis in Alzheimer's disease. PLoS One 3, e3108.

Ulrich J., Meier-Ruge W., Probst A., Meier E., Ipsen S. (1990) Senile plaques: staining for acetylcholinesterase and A4 protein: a comparative study in the hippocampus and entorhinal cortex. Acta Neuropathol. 80, 624-628.

Viayna E., Sabate R., Muñoz-Torrero D. (2013) Dual inhibitors of $\beta$-amyloid aggregation and acetylcholinesterase as multi-target anti-Alzheimer drug candidates. Curr. Top. Med. Chem. 13, 1820-1842.

Weikert T., Rathjen F.G., Layer P.G. (1994) Use of ELISA to G4 antigen to quantitate neurite outgrowth in the chick both in vivo and in vitro. J. Neurochem. 62, 15701577.

Wright C.I., Geula C., Mesulam M.M. (1993) Neurological cholinesterases in the normal brain and in Alzheimer's disease: relationship to plaques, tangles, and patterns of selective vulnerability. Ann. Neurol. 34, 373-384.

Xie J., Jiang H., Wan Y.H. et al. (2011) Induction of a 55 kDa acetylcholinesterase protein during apoptosis and its negative regulation by the Akt pathway. J. Mol. Cell. Biol. 3, 250-259.

Zimmermann M., Borroni B., Cattabeni F., Padovani A., Di Luca M. (2005) Cholinesterase inhibitors influence APP metabolism in Alzheimer disease patients. Neurobiol. Dis. 19, 237-242. 


\section{FIGURE LEGENDS}

$\mathbf{A}$

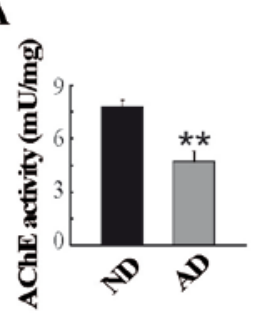

B

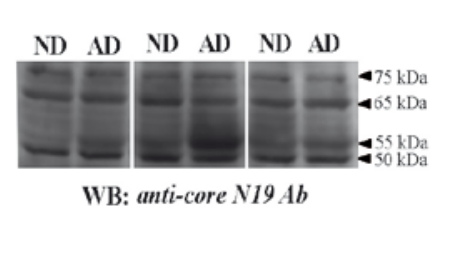

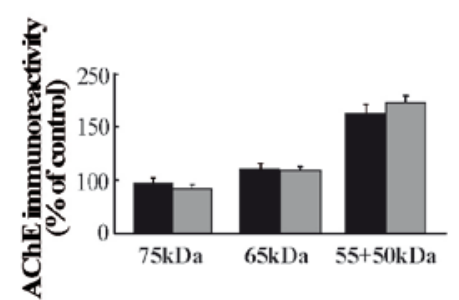

Figure 1. Decrease in AChE activity does not parallel changes in AChE protein in the Alzheimer's brain. (A) AChE activity levels in frontal cortex extracts from nondemented (ND) controls $(n=5)$ and patients with Alzheimer's disease (AD) $(n=5)$. (B) Aliquots of the same brain extracts were immunoblotted with the anti-AChE antibody N19, which recognizes all variants. Representative immunoblot (left panel) and densitometric quantification (right panel) of the AChE-immunoreactive bands, expressed in arbitrary units (a u.), are shown. For the semiquantitative analysis, protein levels were normalized to GAPDH. The results were confirmed in two independent determinations with equivalent amounts of protein loaded in each lane. Columns represent means \pm SEM. *Significantly different $(p<0.05)$ from the ND group. 

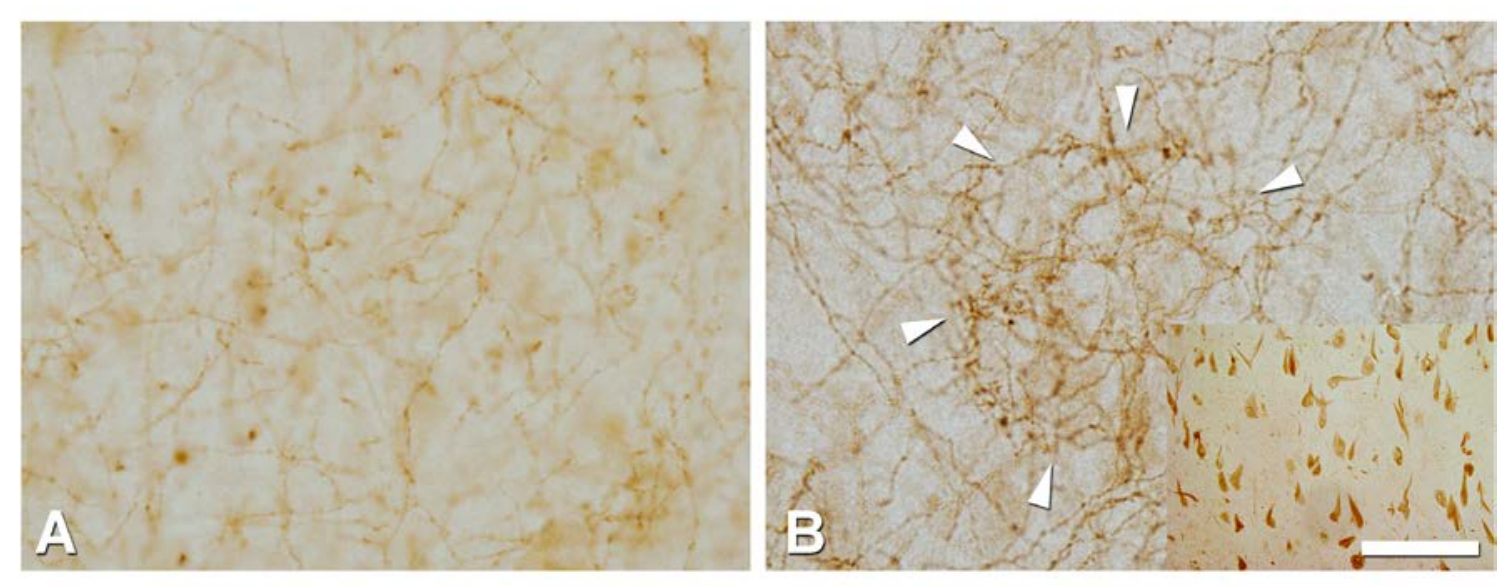

Figure 2. Immunohistochemical detection of AChE in human hippocampus.

Immunostaining with the anti-AChE antibody N19, in the subiculum from a control case (A), and an AD patient (B). Inset in B correspond to AChE enzymatic reaction in the subiculum from the same AD subject. AChE-positive fibers stained with the N19 antibody seem to be denser around amyloid plaques (surrounded by arrow heads). When the AChE enzymatic reaction was performed no fibers were observed but the amyloid plaques and NFT (inset in B) were stained. Scale bar: 35 $\mu \mathrm{m}$ in A, B; $80 \mu \mathrm{m}$ in inset in B. 